\title{
The Effect of Book Storage on Circulation Service
}

Mr. Grieder is assistant director, Stanford University Libraries.

$\mathrm{T}$

HE LARGer libraries of the country, 1 faced with the problem of housing huge annual increments in overflowing stack facilities, have in large measure accepted warehouse storage as a feasible method of mitigating their difficulties. Behind this acceptance is the premise that a sizable proportion of any such library is little used and does not require the accessible location and the immediate service needed for those books which are in heavier demand.

A strong probability in favor of this belief can be established by a cursory examination of any great library. But no method has yet been devised for estimating in an exact sense the effect of a given storage scheme on library services. Before concrete plans are drawn, it would seem desirable to find some basis other than conjecture for deciding how many volumes might reasonably be stored without serious detriment to service. Such a determination would be of value not only in deciding the size and location of storage facilities, but also in making possible intelligent decisions regarding the size and nature of the service organization which they would require.

The Stanford University Library is fortunate in having had sufficient stack space for some 35 years of growth. Within a few years this space will be exhausted, and some means of expanding it will have to be found. The physical situation of the library leaves the way open for several alter- natives. There is plenty of room adjoining the main stack, if the latter were to be expanded, and the campus is large enough to offer many excellent building sites at distances up to five or six miles from the central library if more remote storage in cheaper quarters were desired. Moreover, any cooperative plan is likely to arouse interest because of the existence in the Bay Area of many college and public libraries, including two with more than a million volumes and one with half a million.

As a preliminary to the formulation of any specific plan for adding stack space, two studies were recently conducted at Stanford, the results of which appear in the accompanying table, "Stanford University Libraries: Circulation of Books from Main Stack." These studies refer only to the circulating volumes in the main stacks. Reference works and bound serials, which do not circulate to students at Stanford, were omitted. An estimate was first made of the number of circulating volumes in each broad subject class by using the shelflist and surveying the shelves. All volumes currently charged were included in the total. A two-man team then sampled each class by taking the first circulating volume from each shelf and recording its last date of circulation as shown on the date slip. Volumes which had apparently never circulated were entered by accession date, which could be accurately determined since the inclusive accession numbers for each year of the library's history are known. The sample ratios established by this procedure 
Stanford University Libraries

Circulation of Books from Main Stack

Cumulated distribution of books from main stack by date of last circulation compared with cumulated distribution of books currently circulated by date of last previous circulation ${ }^{1}$

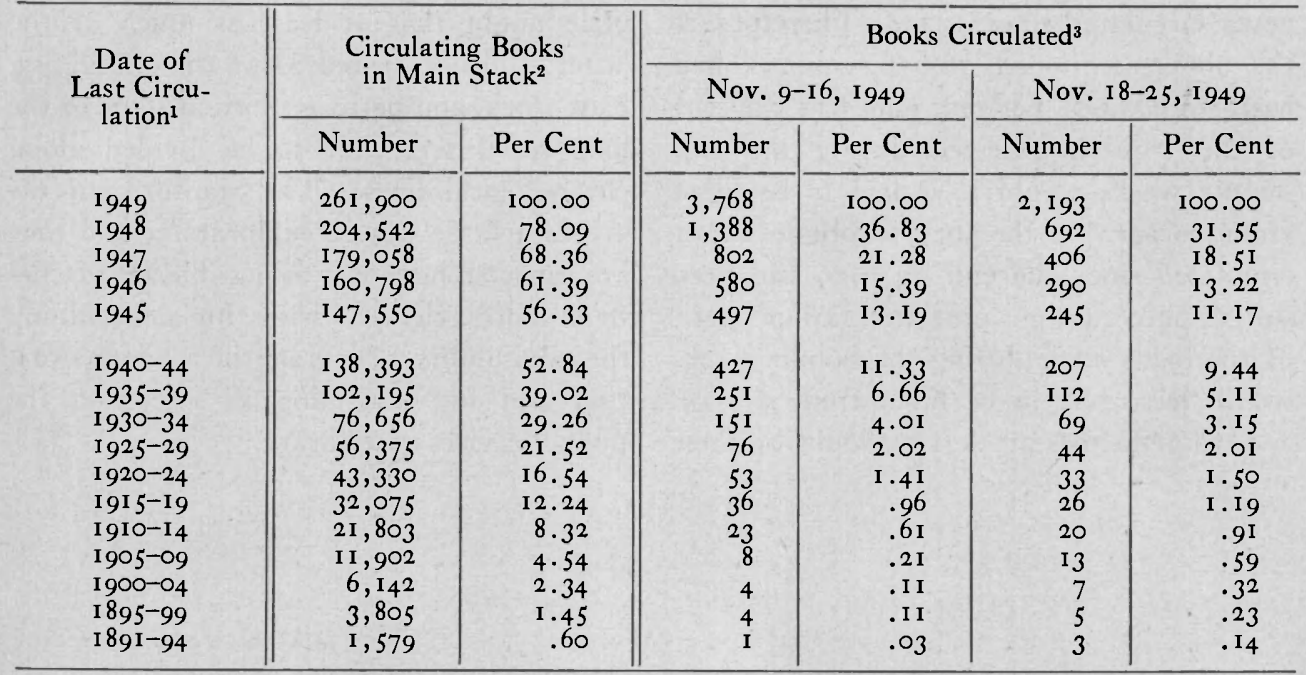

1 Books never circulated were distributed by date of accessioning.

2 Based on samples at an average ratio of $\mathrm{I}$ to $3 \mathrm{I}$ and consisting of first circulating book on each shelf. Corrected for books in use. Non-circulating materials were excluded.

Includes all books circulated from main loan desk, November 9-16 and November 18-25, 1949.

varied from class to class, the average being I : 3 I for all classes.

After this sampling of shelved volumes in a class had been completed, the outstanding charges for that class were counted. These all represented 1949 charges, but only a portion corresponding to the sample ratio for the class was incorporated into the figures. The entire class, that is, was treated as though all outstanding volumes had been recalled, reshelved and sampled as one group with the remainder. Before adding the sample of current charges to the I 949 charges recorded from the stacks, an equal number of shelf samples was struck out on the theory that if the charged volumes had been redistributed on the shelves, they would have fallen more or less evenly throughout the class. Some of them would therefore have been picked off the shelves instead of the volumes which were actually recorded.
The sample reading illustrates the utility of the table in giving at least a rough idea of the impact on loan services to be expected from the segregation of certain materials. It appears, for instance, that 29.26 per cent of the circulating volumes in the main library in 1949 had not been charged out since the end of 1934. As far as circulation is concerned, that percentage, numbering 76,656 volumes, could have been placed in storage with no substantial disruption of the service.

A sample, however, is not the whole of a class, especially one based on so small a ratio. It therefore seemed advisable to discover how many books currently requested would have required searching in storage. This was accomplished by recording the last previous circulation date for each volume charged at the main desk during two sample weeks in November 1949. Again, those volumes never before charged were 
recorded by their accession dates. Referring once more to the table, it appears that 4.01 per cent and 3.15 per cent of the volumes charged during the two sample weeks had never circulated since 1934. Therefore, if the above-mentioned 76,656 volumes had been stored, 4.01 per cent and 3.15 per cent of the requests received during the two sample weeks would have had to be filled from storage. If the 56,375 volumes never circulated since the end of 1929 had been stored, only 2.02 per cent and 2.01 per cent of the loans made during the sample weeks would have had to be filled from storage.

Several factors are left in doubt by these surveys. No attempt was made to measure use of books in the stacks or the amount of noncirculating material which might fall into the little-used category. There seems little doubt that at least as much of the latter could be stored as of the circulating book stock, and perhaps more, if some of the long serial sets were to be divided along chronological lines. The Stanford surveys are to a large degree exploratory, and they are reported here only as possible approaches to a more scientific basis for determining the advisability of storage in a given situation and for predicting its effect on the public services of a library.

\section{The Lamont Library}

(Continued from page 37I)

information or they lead to sources of more complete or more specific information.

The classic writings, important treatises, basic texts and representative authors are to be found in the general collection. The student is referred to another library for other materials.

The reference staff as well as the other sections of the staff constantly work through the collection to eliminate superseded or unused materials. At the same time, the staff systematically reviews the needs of the undergraduate as reflected in assigned and collateral reading and in special assignments, and selects materials from the current and second-hand book market to recommend for acquisition. An essential working collection and a reference staff thoroughly acquainted with its content are thus achieved.

\section{Conference of Eastern College Librarians}

The Conference of Eastern College Librarians, which did not meet last year, will be held on November 25 at Columbia University. The program will include discussions of library cooperation and new technical developments in library service. 